\title{
HIGHLIGHTS
}

TESTICULAR CANCER

\section{Does the dose intensity of BEP chemotherapy affect survival?}

Most patients with metastatic germ cell tumors (GCTs) are considered to have a good prognosis: cure rates $>90 \%$ have been reported since the introduction of bleomycin, etoposide and cisplatin (BEP) chemotherapy regimens. Several studies have since attempted to reduce the toxicity associated with these regimens while maintaining high rates of cure.

In 2001, the Australian and New

Zealand Germ Cell Trials Group (ANZGCTG) published the results of their study that compared two standard BEP regimens-a four-cycle, less-dose-intense regimen and a three-cycle, more-doseintense regimen-in 166 patients with good-prognosis metastatic GCT according to the modified Memorial Sloan-Kettering criteria. The group has now reported an updated analysis of the long-term survival rates and adverse effects associated with these two BEP regimens.

Patients were randomly allocated to receive either $3 \mathrm{~B}_{90} \mathrm{E}_{500} \mathrm{P}$ (three cycles; bleomycin $30 \mathrm{kU}$ on days 1, 8 and 15; etoposide $100 \mathrm{mg} / \mathrm{m}^{2}$ on days $1-5$; cisplatin $20 \mathrm{mg} / \mathrm{m}^{2}$ on days $1-5$ ) or $4 \mathrm{~B}_{30} \mathrm{E}_{360} \mathrm{P}$ (four cycles; bleomycin $30 \mathrm{kU}$ on day 1 ; etoposide
$120 \mathrm{mg} / \mathrm{m}^{2}$ on days $1-3$; cisplatin $100 \mathrm{mg} /$ $\mathrm{m}^{2}$ on day 1$)$. After a median follow-up duration of 33 months, a significant survival benefit was observed for the moredose-intense $3 \mathrm{~B}_{90} \mathrm{E}_{500} \mathrm{P}$ regimen compared to the $4 \mathrm{~B}_{30} \mathrm{E}_{360} \mathrm{P}$ regimen (3-year survival $90 \%$ versus $81 \%, P=0.008)$, and the trial was subsequently stopped.

To assess whether the observed survival benefit was maintained in the long term, the current analysis included a median follow-up duration of 8.5 years; all but five survivors were followed for at least 5 years. The 8-year survival rate remained higher in the patients receiving $3 \mathrm{~B}_{90} \mathrm{E}_{500} \mathrm{P}$ regimen compared to the $4 \mathrm{~B}_{30} \mathrm{E}_{360} \mathrm{P}$ regimen ( $92 \%$ versus $83 \%, P=0.037$ ). 8 -year progression-free survival was also higher in the $3 \mathrm{~B}_{90} \mathrm{E}_{500} \mathrm{P}$ group (86\% versus $79 \%$ ), although the difference was not statistically significant. Adverse effects and quality-of-life scores after the completion of treatment tended to favor the $3 \mathrm{~B}_{90} \mathrm{E}_{500} \mathrm{P}$ regimen, particular those for numbness $(P=0.003)$ and hair loss $(P=0.04)$.

The findings of this study suggest that the three-cycle, more-dose-intense BEP regimen is associated with superior long-

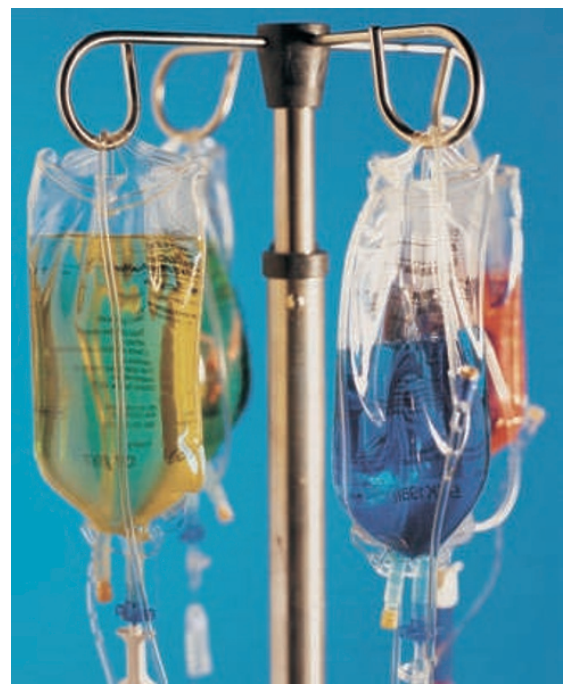

term survival compared to the four-cycle, less-dose-intense regimen. Although the authors note that they can not identify with certainty which of the specific differences between the two treatment protocols best account for the observed improvement in survival, they consider that the difference in etoposide dose intensity is the most likely explanation.

Nick Warde

Original article Grimison, P. S. et al. Comparison of two standard chemotherapy regimens for good-prognosis germ cell tumors: updated analysis of a randomized trial. J. Natl Cancer Inst. doi:10.1093/jnci/djq245 